\title{
RESEARCH ON CALCULATION OF GRINDING SURFACE ROUGHNESS
}

\author{
Van Nga Tran Thi \\ Faculty of Mechanical Engineering ${ }^{l}$ \\ Khanh Nguyen Lam \\ Faculty of Mechanical Engineering ${ }^{l}$ \\ Cuong Nguyen Van $\bowtie$ \\ Faculty of Mechanical Engineering ${ }^{l}$ \\ nguyencuong@utc.edu.vn \\ ${ }^{1}$ University of Transport and Communications \\ 3 Cau Giay str., Hanoi, Vietnam, 11512
}

$\bowtie$ Corresponding author

\begin{abstract}
In machining processes, grinding is often chosen as the final machining method. Grinding is often chosen as the final machining method. This process has many advantages such as high precision and low surface roughness. It depends on many parameters including grinding parameters, dressing parameters and lubrication conditions. In grinding, the surface roughness of a workpiece has a significant influence on quality of the part. This paper presents a study of the grinding surface roughness predictions of workpieces. Based on the previous studies, the study built a relationship between the abrasive grain tip radius and the Standard marking systems of the grinding wheel for conventional and superabrasive grinding wheels (diamond and CBN abrasive). Based on this, the grinding surface roughness was predicted. The proposed model was verified by comparing the predicted and experimental results. Appling the research results, the surface roughness when grinding three types of steel D3, A295M and SAE 420 with $\mathrm{Al}_{2} \mathrm{O}_{3}$ and $\mathrm{CBN}$ grinding wheels were predicted. The predicted surface roughness values were close to the experimental values, the average deviation between predictive results and experimental results is $15.11 \%$ for the use of $\mathrm{Al}_{2} \mathrm{O}_{3}$ grinding wheels and $24.29 \%$ for the case of using CBN grinding wheels. The results of the comparison between the predicted model and the experiment show that the method of surface roughness presented in this study can be used to predict surface roughness in each specific case.

The proposed model was verified by comparing the predicted and measured results of surface hardness. This model can be used to predict the surface hardness when surface grinding.
\end{abstract}

Keywords: Predicted grinding surface roughness, abrasive grain tip radius, surface roughness.

DOI: $10.21303 / 2461-4262.2022 .001832$

\section{Introduction}

Surface quality when grinding is assessed through many parameters: hardness, surface layer residual stress, surface roughness. In particular, surface roughness is one of the parameters that greatly affect the ability to work and the life of the machine details and it is often chosen as parameters for evaluation of the grinding process.

For studying grinding roughness surface, experimental methods are often used. However, the experimental method has the disadvantage that the results obtained in the experimental process are usually applied only under similar conditions and the experimental cost is large [1]. Therefore, the study of modeling - simulating the grinding process to predict surface roughness will overcome the above limitations.

The studies in this field have been carried out by many researchers, such as building models to predict surface roughness when grinding based on the analysis models of cutting thickness [2]; prediction the surface roughness when grinding with the assumption that the grits are uniformly distributed on the grinding wheel surface [3-5]; prediction the surface roughness when grinding through determining the average value of the depth of the cut into the machining surface of the abrasive grains [6]; applying probability theory when analyzing the cutting process of abrasive 
grains to predict surface roughness [7]; prediction surface roughness with the assumption that the grinding process is a mechanical - thermal equilibrium process [8]; build the relationship between surface roughness and unformed chip thickness when it was assumed that the cross section of each cut is made by an abrasive left on the surface of the workpiece with different geometric shapes (triangle, semicircular, curved, hyperbole) [1,9-11].

However, the applicability of the results of these studies is quite difficult because of the micro-structure of the grinding wheel surface [1]. Therefore, it is necessary to build the correlation between the microstructure of the grinding wheel surface and its parameters, which will be the basis for predicting the achieved surface roughness by grinding.

\section{Materials and Methods}

The model for prediting grinding surface roughness is presented in the following formula [12-14]:

$$
R_{a}=\frac{0.25 \cdot v_{w}^{0.4} \cdot a_{p}^{0.6}}{K_{C}^{0.4} \cdot\left(v_{s}+v_{W}\right)^{0.4} \cdot n_{g}^{0.4} \cdot D_{e}^{0.2} \cdot \rho_{g}^{0.2}} .
$$

In (1): $v_{w}$ is the workpiece velocity; $a_{p}$ is the depth of cut; $K_{c}$ is the chip generation coefficient, the definite of the value of this parameter is often difficult, in most cases it is possible to choose $K_{c}=0.9$ [12]; $v_{s}$ is the grinding wheel velocity; $n_{g}$ is the number of abrasive particles per unit area of the grinding wheel surface; $D_{e}$ is the equivalent abrasive grains' diameter; $\rho_{g}$ is the radius of the abrasive grain's top.

The determination of these parameters will be discussed in detail in this study.

The equivalent grinding wheel diameter is determined as follows [15, 16]:

$$
d_{e}=\frac{d_{s} \cdot d_{W}}{d_{s} \pm d_{W}} .
$$

In which, $d_{s}, d_{W}$ respectively are grinding wheel diameter and workpieces diameter. The plus sign $(+)$ in formula (2) is used when external grinding, minus sign $(-)$ is used for internal grinding. When grinding flat, $d_{W}$ to infinity, so that $d_{e}$ as $d_{s}$.

The depth of cut is determined as follows [12-14]:

$$
a_{p}=0.739 \cdot t+\sqrt{0.546 \cdot t^{2}+\frac{13.55 \cdot v_{W} \cdot t}{K_{C} \cdot\left(v_{s} \pm v_{W}\right) \cdot n_{g} \cdot \sqrt{d_{e} \cdot \rho_{g}}}} .
$$

Where $t$ is the depth of the layer of metal removed after grinding. The plus sign (+) in formula (3) is used when external grinding, minus sign (-) is used for internal grinding.

Regarding the abrasive grain tip radius $\rho_{g}$, this parameter depends on the limit size of abrasive grain $B_{g}$. However, the Standard marking systems of the grinding wheel does not indicate the abrasive grain tip radius or the limit size of abrasive grain. Therefore, it is necessary to find a solution to determine the abrasive grain tip radius from the Standard marking systems of the grinding wheel. Currently, there are two popular Systems of Standard marking systems of the grinding wheel being used by grinding wheel manufacturers: the Standard marking systems according to ISO 8486-1.2:1996 (E) standard and GOST R 3647-80 standard.

According to ISO 8486-1.2:1996 (E), the grain size is denoted by a number and by the letter $F$. In Table 1, the values of the limit size of abrasive grain $B_{g}$ and the abrasive grain tip radius $\rho_{g}$ have been determined in some of experimental studies.

From the data in Table 1, the relationship between the abrasive grain tip radius $\rho_{g}$ and the limit size of abrasive grain $B_{g}$ is shown in equation (4). Alternatively, the relationship between the abrasive grain tip radius $\rho_{g}$ and denoted Grain size $F$ is presented in (5):

$$
\rho_{g}=0.0535 \cdot B_{g}^{0.955},
$$




$$
\rho_{g}=0.8754 \cdot F^{0.9659} \text {. }
$$

The data in Table 2 shows that the value of the abrasive grain tip radius when calculated according to formulas (4), (5) are very close to the experimental value. For formula (4), the values of deviation are (0.09-5.77) \%, and for formula (5) the values of deviation is $(0.79-6.55) \%$. Therefore, it is shown that one of the two formulas can be used to calculate the value of the abrasive grain tip radius for each grinding wheel according Standard marking systems ISO 8486-1.2:1996 (E).

\section{Table 1}

The values of parameters of the denoted grinding wheel according to ISO 8486-1.2:1996 (E) standard [15-23]

\begin{tabular}{|c|c|c|c|c|c|c|c|c|c|c|}
\hline \multicolumn{11}{|c|}{ Denoted Grain size, $F$} \\
\hline 16 & 25 & 32 & 40 & 50 & 63 & 80 & 100 & 125 & 160 & 200 \\
\hline \multicolumn{11}{|c|}{ The limit size of abrasive grain $B_{g}, \mu \mathrm{m}$} \\
\hline 160 & 240 & 315 & 400 & 500 & 630 & 800 & 1000 & 1250 & 1600 & 2000 \\
\hline \multicolumn{11}{|c|}{ The abrasive grain tip radius $\rho_{g}, \mu \mathrm{m}$} \\
\hline- & - & 26 & - & - & 45 & - & - & - & 117 & - \\
\hline 13 & 19 & - & 28 & - & - & - & - & - & 114 & - \\
\hline 11 & 17 & 25 & - & 41 & - & - & 76 & - & - & - \\
\hline- & 19 & - & 30 & - & - & 68 & - & 97 & 115 & 130 \\
\hline 14 & 21 & - & 30 & - & - & - & - & - & - & - \\
\hline- & 18 & 26 & - & 43 & - & - & 80 & 91 & - & 138 \\
\hline 12 & - & - & - & - & 48 & - & - & 93 & 119 & 149 \\
\hline 13 & 19 & 27 & 28 & 38 & - & 60 & - & - & - & - \\
\hline \multicolumn{11}{|c|}{ Mean } \\
\hline 12.6 & 19 & 26 & 29 & 39.5 & 48 & 64 & 76 & 95 & 115.3 & 139.5 \\
\hline
\end{tabular}

Table 2

Presents the abrasive grain tip radius when calculated using (4), (5) and the values in experimental studies (data from Table 1)

\begin{tabular}{cccccccccccc}
\hline \multicolumn{10}{c}{ Denoted Grain size, $\boldsymbol{F}$} \\
\hline 16 & 25 & 32 & 40 & 50 & 63 & 80 & 100 & 125 & 160 & 200 \\
\hline \multicolumn{10}{c}{} & \multicolumn{10}{c}{ The limit size of abrasive grain $\boldsymbol{B}_{\boldsymbol{g}}, \boldsymbol{\mu m}$} \\
\hline 160 & 240 & 315 & 400 & 500 & 630 & 800 & 1000 & 1250 & 1600 & 2000 \\
\hline 12.6 & 19 & 26 & 29 & 39.5 & 48 & 64 & 76 & 95 & 115.3 & 139.5 \\
12.8 & 19.4 & 24.5 & 30.7 & 38.1 & 47.6 & 59.6 & 74.3 & 92.4 & 115.4 & 143 \\
1.59 & 2.11 & 5.77 & 5.86 & 3.54 & 0.83 & 6.88 & 2.24 & 2.74 & 0.09 & 2.51 \\
12.7 & 19.6 & 24.9 & 30.9 & 38.3 & 47.9 & 60.3 & 74.8 & 92.8 & 117.8 & 146.1 \\
0.79 & 3.16 & 4.23 & 6.55 & 3.04 & 0.21 & $5.78 \%$ & $1.58 \%$ & 2.32 & 2.17 & 4.73
\end{tabular}

Another Standard marking systems of grinding wheel used by grinding wheel manufacturers to denote grinding wheel is the GOST R 3647-80 standard. According to this standard, the size of abrasive grain is expressed through the number of sieve holes per square inch of sieve used for grading and it is denoted $M$. Table 3 presents the abrasive grain tip radius of some grades.

From the data in Table 3, the relationship between the abrasive grain tip radius and the $M$ index is built in (6):

$$
\rho_{g}=1245.5 \cdot M^{-1.132}
$$


Table 4 presents the calculated abrasive grain tip radius using Equation (6) and experimental value (data from Table 3).

Table 3

The values of the abrasive grain tip radius $\rho_{g}$ to GOST R 3647-80 standard

\begin{tabular}{ccc}
\hline $\mathbf{M}$ & $\boldsymbol{B}_{\boldsymbol{g}}(\boldsymbol{\mu \mathbf { m }})$ & $\rho_{g}(\boldsymbol{\mu m})$ \\
\hline 10 & 2250 & 85.1 \\
12 & 1800 & 68.7 \\
16 & 1425 & 55.0 \\
20 & 1125 & 43.9 \\
24 & 900 & 35.5 \\
30 & 715 & 28.5 \\
36 & 565 & 22.7 \\
46 & 450 & 18.3 \\
54 & 357.5 & 14.7 \\
60 & 282.5 & 11.7 \\
70 & 225 & 9.4 \\
80 & 180 & 7.6 \\
100 & 142.5 & 6.2 \\
120 & 112.5 & 5.4 \\
150 & 90 & 4.2 \\
180 & 71.5 & 3.7 \\
230 & 56.5 & 2.4 \\
280 & 40 & 2.0
\end{tabular}

Table 4

Comparing the abrasive grain tip radius according to the predicted results and experimental results of the denoted grinding wheel according to GOST R 3647-80 standard

\begin{tabular}{cccc}
\hline \multirow{2}{*}{$\begin{array}{c}\text { Denoted } \\
\text { grain size }\end{array}$} & $\begin{array}{c}\text { Experimental } \\
\text { value in Table } 3\end{array}$ & The calculated values by formula (6) & $\rho_{\boldsymbol{g}}$ \\
\cline { 3 - 4 } & 85.1 & 91.9 & Deviation from experimental values (\%) \\
\hline 10 & 68.7 & 74.8 & 7.99 \\
12 & 55.0 & 54.0 & 8.88 \\
16 & 43.9 & 41.9 & 1.82 \\
20 & 35.5 & 34.1 & 4.56 \\
24 & 28.5 & 26.5 & 3.94 \\
30 & 22.7 & 21.6 & 7.02 \\
36 & 18.3 & 16.3 & 4.85 \\
46 & 14.7 & 13.6 & 10.93 \\
54 & 11.7 & 12.1 & 7.48 \\
60 & 9.4 & 10.2 & 3.42 \\
70 & 7.6 & 8.7 & 8.51 \\
80 & 6.2 & 6.8 & 14.47 \\
100 & 5.4 & 5.5 & 9.68 \\
120 & 4.2 & 4.3 & 1.85 \\
150 & 3.7 & 3.5 & 2.38 \\
180 & 2.4 & 2.6 & 5.41 \\
230 & 2.0 & 2.1 & 8.33 \\
280 & 1.7 & 1.8 & 5.00 \\
320 & & & 5.88
\end{tabular}

The data in Table 4 show that the calculated abrasive grain tip radius (6) is very close to the experimental value, the deviation from $1.82 \%$ to $14.7 \%$. Therefore, it is shown that (6) can be 
used to calculate the calculated abrasive grain tip radius for each grinding wheel according to the GOST R 3647-80 standard.

The number of abrasive grains per unit area of grinding wheel surface is determined by the following formula [15]:

$$
n_{g}=\frac{6 \cdot \epsilon}{\pi \cdot B_{g}^{2}}
$$

In $(7) \in$ is the percentage of volume of grain in the grinding wheel. For conventional grinding wheel, it is determined by the (8) [15], with the index of the structure number of the grinding wheel. For diamond grinding wheel and $\mathrm{CBN}$ grinding wheel, the value of the grinding wheel investigated according to the index showing the concentration of abrasive particles as shown in Table 5 [24]:

$$
\in(\%)=2 \cdot(32-S)
$$

The data in Table 5 shows that if the index denotes the concentration of abrasive grains of diamond and CBN grinding wheel, the value of is determined by (9):

$$
\in(\%)=0.25 \cdot C
$$

In the case of a medium structure grinding wheel, for simple denotation of grinding wheel, there are some grinding wheel manufacturers do not show the structure of the grinding wheel in their Standard Marking Systems. In this case, for a conventional grinding wheel it is possible to choose a structure $S=8$, but for diamond or CBN grinding wheel, choose $C=100$ [15].

Table 5

Relationship between $\epsilon$ and index showing abrasive concentration of diamond and CBN grinding wheels [24]

\begin{tabular}{ccccccccc}
\hline Concentration, $\boldsymbol{C}$ & $\mathbf{2 5}$ & $\mathbf{5 0}$ & $\mathbf{7 5}$ & $\mathbf{1 0 0}$ & $\mathbf{1 2 5}$ & $\mathbf{1 5 0}$ & $\mathbf{1 7 5}$ & $\mathbf{2 0 0}$ \\
\hline$\in(\%)$ & 6.25 & 12.50 & 18.75 & 25.00 & 31.25 & 37.50 & 43.75 & 50.00
\end{tabular}

From the (1)-(9) show that it is possible to predict the grinding surface roughness according to each specific case of the parameters of the grinding wheel, the dimension of workpiece and the parameters of cutting mode. In particular, if the grinding wheel is denoted according to ISO 8486-1.2:1996 (E), the abrasive grain tip radius is calculated by the formula (4) or (5), and if the grinding wheel is denoted according to with GOST R 3647-80 standard, the abrasive grain tip radius is calculated (6). The percentage of the abrasive grits in a grinding wheel is calculated (8) with a conventional grinding wheel or (9) with the CBN or diamond grinding wheel.

\section{Results and discussion}

Experimental results using $\mathrm{Al}_{2} \mathrm{O}_{3}$ with marking 36A60LV and $\mathrm{CBN}$ with marking $\mathrm{HY}-100$ \# for grinding three materials including D3, A295M and SAE 420 on the flat grinding machine in the study [25] will be used to compare with values when calculating in this study.

Grinding wheel parameters and technological regime parameters used during the experiment of the study [25] are presented in Table 6 for cases of using $\mathrm{Al}_{2} \mathrm{O}_{3}$ grinding wheel and in Table 7 for CBN grinding wheel. The experimental surface roughness values when grinding the different materials and the calculated surface roughness values (1) to (9) were also included in Tables 6, 7.

From the data in Tables 6, 7, roughness comparison charts were built as shown in Fig. 1, 2, respectively for grinding by $\mathrm{Al}_{2} \mathrm{O}_{3}$ and $\mathrm{CBN}$ grinding wheels. In which $\mathrm{R}_{\mathrm{a}(1)}, \mathrm{R}_{\mathrm{a}(2)}, \mathrm{R}_{\mathrm{a}(3)}$ are the surface roughness when grinding D3 steel, A295M steel and SAE420 steel respectively, and $\mathrm{R}_{\mathrm{a}\left({ }^{*}\right)}$ is the measured surface roughness. 
Table 6

The experimental surface roughness values [25] and the calculated surface roughness values using $\mathrm{Al}_{2} \mathrm{O}_{3}$ grinding wheel

\begin{tabular}{ccccccc}
\hline & & & \multicolumn{4}{c}{ Surface roughness, $\mathbf{R a}$} \\
\cline { 3 - 6 } No. & $\boldsymbol{a}_{\boldsymbol{p}}(\mathbf{m m})$ & $\boldsymbol{v}_{\boldsymbol{W}}(\mathbf{m} / \mathbf{m i n})$ & \multicolumn{3}{c}{ The experimental surface roughness } & \multirow{2}{*}{$\mathbf{R}_{\mathbf{a}(*)}$} \\
\cline { 3 - 6 } & & 8 & $\mathbf{R}_{\mathbf{a}(\mathbf{1})}$ & 0.41 & 0.46 & 0.54 \\
\hline 1 & 0.05 & 8 & 0.45 & 0.48 & 0.32 & 0.43 \\
2 & 0.035 & 15 & 0.42 & 0.55 & 0.50 & 0.69 \\
3 & 0.05 & 15 & 0.55 & 0.55 & 0.62 & 0.56
\end{tabular}

Table 7

The experimental surface roughness values $v s$ the calculated surface roughness values using CBN grinding wheel

\begin{tabular}{|c|c|c|c|c|c|c|}
\hline \multirow{3}{*}{ No. } & \multirow{3}{*}{$a_{p}(\mathrm{~mm})$} & \multirow{3}{*}{$v_{W}(\mathrm{~m} / \mathrm{min})$} & \multicolumn{4}{|c|}{ Surface roughness, $\mathbf{R a}$} \\
\hline & & & \multicolumn{3}{|c|}{ The experimental surface roughness } & \multirow{2}{*}{$\mathbf{R}_{\mathbf{a}(*)}$} \\
\hline & & & $\mathbf{R}_{\mathrm{a}(1)}$ & $\mathbf{R}_{\mathrm{a}(2)}$ & $\mathbf{R}_{\mathrm{a}(3)}$ & \\
\hline 1 & 0.01 & 5 & 0.50 & 0.32 & 0.23 & 0.39 \\
\hline 2 & 0.02 & 5 & 0.63 & 0.38 & 0.32 & 0.59 \\
\hline 3 & 0.01 & 15 & 0.82 & 0.65 & 0.6 & 0.60 \\
\hline 4 & 0.02 & 15 & 1.06 & 0.55 & 0.64 & 0.92 \\
\hline
\end{tabular}

Chart Title

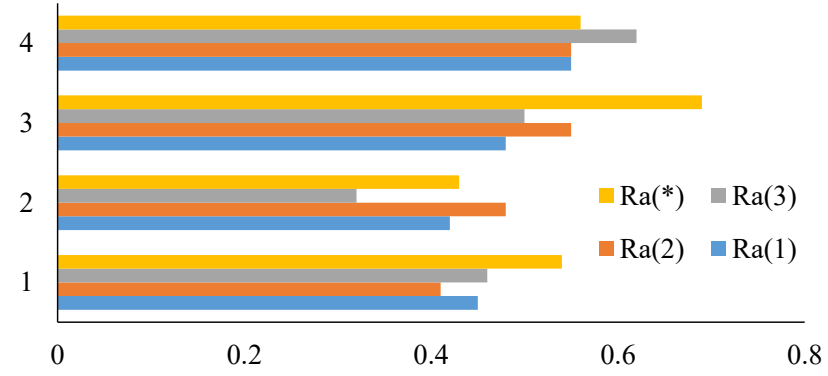

Fig. 1. The experimental surface roughness values $v s$ the calculated surface roughness values using $\mathrm{Al}_{2} \mathrm{O}_{3}$ grinding wheel

Chart Title

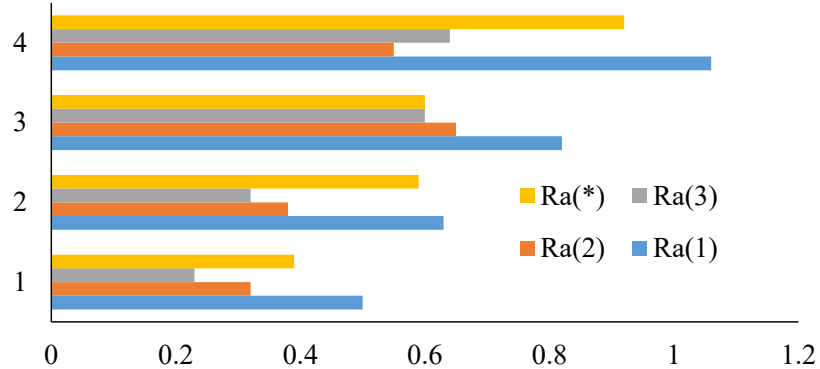

Fig. 2. The experimental surface roughness values $v s$ the calculated surface roughness values using $\mathrm{Al}_{2} \mathrm{O}_{3}$ grinding wheel

Tables 6, 7 and Fig. 1, 2 show that: In the case of using $\mathrm{Al}_{2} \mathrm{O}_{3}$, the calculated surface roughness values is close to the experimental surface roughness values for all three steel types testing. The average, deviation calculated for all three steel types testing is $15.11 \%$. As for the case of using CBN grinding wheel, the average deviation between calculated results and experimental results is about $24.29 \%$. These results show that the method of surface roughness presented in this study can be used to predict surface roughness in each specific case. 
The difference between the calculated results and the measurement results can be explained by the fact that in the calculation process, random problems arising in the grinding process have not been taken into account. The problems arising in the grinding process can be listed as: the hardness of the workpiece is not uniform, the change of the cooling lubrication technology, and especially the problem of vibration during grinding. Therefore, issues that need to be controlled before grinding include: ensuring the homogeneity of the workpiece, using the lubrication parameters recommended by the manufacturer, and minimizing vibrations forced during grinding (enhance machine rigidity, balance grinding wheel, repair grinding wheel regularly, etc.). The addition of this information to the surface roughness calculation formulas is the direction for further studies.

\section{Conclusions}

Based on the inheritance and development of the published results of surface roughness modeling when grinding, this study presents a method to determine the abrasive grain tip radius based on the different Standard marking systems of the grinding wheel. The formula for calculating the percentage of grinding grain volume in diamond and CBN grinding wheel was also introduced in this study. The method of predicting surface roughness when grinding with conventional grinding wheel, diamond or CBN grinding wheel was also clarified in this study. The accuracy of these methods has been verified by comparing roughness values when calculating and experimenting. The results show that the roughness value when calculating and experimenting is very compatible with each other. For $\mathrm{Al}_{2} \mathrm{O}_{3}$ grinding wheel, the difference between calculation result and measurement result is only $15.11 \%$, and the difference is equal to $24.29 \%$ for CBN grinding wheel. So that, the results presented in this study can be used to predict the grinding surface roughness, contributing to reducing the time to adjust the machine, machining time, creating conditions that improve the efficiency of the grinding process.

\section{Acknowledgments}

The author would like to express their gratitude with the help of University of Transport and Communications (http://en.utc.edu.vn/) during the implementation of this study.

\section{References}

[1] Hecker, R. L., Liang, S. Y. (2003). Predictive modeling of surface roughness in grinding. International Journal of Machine Tools and Manufacture, 43 (8), 755-761. doi: https://doi.org/10.1016/s0890-6955(03)00055-5

[2] Lal, G. K., Shaw, M. C. (1975). The Role of Grain Tip Radius in Fine Grinding. Journal of Engineering for Industry, 97 (3), 1119-1125. doi: https://doi.org/10.1115/1.3438664

[3] Part 2: Study of the Finish Produced in Surface Grinding (1967). Proceedings of the Institution of Mechanical Engineers, Conference Proceedings, 182 (11), 179-194. doi: https://doi.org/10.1243/pime_conf_1967_182_316_02

[4] Sato, K. (1955). On the surface roughness in grinding. Technology Reports, Tohoku University, 20, 59-70.

[5] Yang, C., Shaw, M. C. (1955). The grinding of titanium alloys. Transactions of ASME, 77, 645-660.

[6] Zhou, X., Xi, F. (2002). Modeling and predicting surface roughness of the grinding process. International Journal of Machine Tools and Manufacture, 42 (8), 969-977. doi: https://doi.org/10.1016/s0890-6955(02)00011-1

[7] Basuray, P. K., Sahay, B., Lal, G. K. (1980). A simple model for evaluating surface roughness in fine grinding. International Journal of Machine Tool Design and Research, 20 (3-4), 265-273. doi: https://doi.org/10.1016/0020-7357(80)90009-8

[8] Chiu, N., Malkin, S. (1993). Computer Simulation for Cylindrical Plunge Grinding. CIRP Annals, 42 (1), 383-387. doi: https:// doi.org/10.1016/s0007-8506(07)62467-6

[9] Khare, S. K., Agarwal, S. (2015). Predictive Modeling of Surface Roughness in Grinding. Procedia CIRP, 31, 375-380. doi: https://doi.org/10.1016/j.procir.2015.04.092

[10] Agarwal, S., Venkateswara Rao, P. (2005). Surface Roughness Prediction Model for Ceramic Grinding. Manufacturing Engineering and Materials Handling, Parts A and B. doi: https://doi.org/10.1115/imece2005-79180

[11] Saxena, K. K., Agarwal, S., Das, R. (2016). Surface Roughness Prediction in Grinding: a Probabilistic Approach. MATEC Web of Conferences, 82, 01019. doi: https://doi.org/10.1051/matecconf/20168201019

[12] Novoselov, Y. K. (2012). The Dynamics of Formation of Surfaces in Abrasive Machining. Sevastopol: Publ. SevNTU, 304.

[13] Novoselov, Y., Bratan, S., Bogutsky, V. (2016). Analysis of Relation between Grinding Wheel Wear and Abrasive Grains Wear. Procedia Engineering, 150, 809-814. doi: https://doi.org/10.1016/j.proeng.2016.07.116 
[14] Novoselov, Y., Bogutsky, V., Shron, L., Kharchenko, A. (2017). Forecasting the surface roughness of the workpiece in the round external grinding. MATEC Web of Conferences, 129, 01080. doi: https://doi.org/10.1051/matecconf/201712901080

[15] Malkin, S., Guo, C. (2008). Grinding Technology: Theory and Application of Machining with Abrasives. Industrial Press Inc., 372.

[16] Marinescu, I. D., Hitchiner, M. P., Uhlmann, E., Rowe, W. B., Inasaki, I. (2006). Handbook of Machining with Grinding Wheels. CRC Press, 632. doi: https://doi.org/10.1201/9781420017649

[17] Bajkalov, A. K. (1978). Introduction to the Theory of Grinding Materials. Kyiv: Naukova dumka.

[18] Maslov, E. N. (1974). Theory of Grinding Materials. Moscow: Mashinostroenie.

[19] Murdasov, A. V., Wolff, A. M. (1967). Peculiarities of Working of Grinding Wheels from Abrasive Grains of Different Shapes. Abrasives and diamonds: scientific technical abstract collection, 4, 65-69.

[20] Vakser, D. B. (1960). The Influence of the Geometry of Abrasive Grains on the Properties of the Grinding Wheel. Moscow: Mashgiz.

[21] Shaw, C. M. (1996). Principles of Abrasive Processing. Oxford University Press, 592.

[22] Korolev, A. V., Novoselov, Yu. K. (1987). Theoretical and Probabilistic Basis of Abrasive Treatment. Saratov: Saratovsk. un-t.

[23] El-Hofy, H. (2018). Fundamentals of Machining Processes. Conventional and Nonconventional Processes. CRC Press, 602. doi: https://doi.org/10.1201/9780429443329

[24] Structure of Grinding Wheel (Structure and Concentration) (2018). Noritake Technikal Journal, 1, 4-5. Available at: https:// www.noritake.co.jp/eng/catalog_type/download/8aa6080c86465c93cfebd53c07689c7f.pdf

[25] Trung, D. D., Son, N. H. (2020). An experimental study on prediction of surface roughness in grinding. International Journal of Mechanical and Production Engineering Research and Development, 10 (1), 47-58.

How to cite: Tran Thi, V. N., Nguyen Lam, K., Nguyen Van, C. (2022). Research on calculation of grinding surface roughness. EUREKA: Physics and Engineering, 1, 85-92. doi: https://doi.org/10.21303/2461-4262.2022.001832 